\title{
Flipped Classroom With Simulation Assists Students Learning the Vector Knowledge
}

\author{
${ }^{1}$ The Chinese University of Hong Kong \\ ${ }^{2}$ The Education University of Hong Kong \\ Email: 1155138248@link.cuhk.edu.hk
}

Correspondence: Ng Siu-Ping, The Chinese University of Hong Kong, Shatin, N.T., Hong Kong.

\author{
Ng Siu-Ping ${ }^{1}$, Fung Chak-Him ${ }^{2}$
}

Received: Oct. 19, 2020

Accepted: Nov. 19, 2020

Online Published: Nov. 29, 2020

doi:10.11114/jets.v8i12.5093

URL: https://doi.org/10.11114/jets.v8i12.5093

\begin{abstract}
Vectors are critically important in mathematics and physics because it forms the basis of the university curriculum, yet it is a challenging task for high-school students. In this study, test papers were distributed to 18 Grade 11 high-school students in Mainland China, while interviews were conducted on four students and one school leader. The analysis of pre- and post-test scores and interviews reveals that flipped classroom with Physics Education Technology $(\mathrm{PhET})$ simulation promotes students' learning performance with $\mathrm{t}(17)=5.818, \mathrm{p}<.001$. In particular, visualization and dragging enhance understanding of the basic concepts of the topic. Not requiring interaction between teachers and students, flipped classroom with PhET simulation contributes to students' learning progress especially when the traditional face-to-face lecture is not available due to special circumstances such as spreading the novel coronavirus (COVID-19). It may also serve as a prototype of artificial intelligence(AI) in education.
\end{abstract}

Keywords: AI in education, flipped classroom, flipped learning, mathematics, PhET simulation, physics, vectors

\section{Introduction \& Background}

The learning of vectors is critical because vectors are a necessary component of mathematical language of physics (Knight, 1995). Most topics of physics require the ability to reason about vectors at the introductory level of university (Nguyen \& Meltzer, 2003). However, various researches report that understanding of the vector concept among university students is far from satisfactory (Barniol \& Zavala, 2009; Knight,1995; Zavala \& Barniol, 2010). This phenomenon can be partly attributed to the absence of complete mastery of vectors among high-school students before receiving tertiary education. Most of them are exposed to vector concepts in high-school mathematics or physics courses (Nguyen \& Meltzer, 2003). In British International Advanced-level mathematics curriculum, 3 out of 14 units consist of vectors (Pearson, 2018), which is the core unit of mathematics. Despite its significance in the syllabus, public examination reports indicate that students' understanding of vectors is lagging behind. For the questions concerning vectors, a significant number of students achieve little or no credit (Pearson Examiners' Report, 2015). Among all the possible factors, lack of visualization may be primarily held accountable for students' poor performance. Successful solutions in vectors almost follow a good diagram (Pearson Examiners' Report, 2016). Yet students often find it hard to imagine the vectors without understanding the concept in a concrete manner. Most of their attempts to solve questions prove to be unsuccessful because students generally ignore the background information and start to work on questions without realizing the rationale behind them.

As a potential remedy to the unsatisfactory performance among students, an alternative teaching method is much needed and flipped classroom enriched by dynamic geometry software (DGS) could be an ideal candidate. According to Bishop and Verleger (2013), flipped classroom is "an educational technique that consists of two parts: interactive group learning activities inside the classroom, and direct computer-based individual instruction outside the classroom" (para 13). Flipped classroom is valued because more class time is available for the teachers to take care of the students. By putting knowledge transfer process outside the classroom, more time could be spent in providing individual guidance and taking care of students' special educational needs (Bishop \& Verleger, 2013). Students' lack of practicum when learning vectors is another major concern among educators, and this can be tackled by introducing interactive computer software for in-class activities because IT-assisted teaching enriches and further enhances teachers' 
pedagogies in activities such as demonstration, simulation, mathematical experiment and exploration (CDC \& HKEAA, 2017). Currently, many interactive software about mathematics and physics are widely accessible, one of which is Physics Education Technology (PhET) simulation "Vector Addition". Directly related to the topic, this software provides an opportunity for students to drag vectors. Dragging is a powerful tool for students to acquire mathematical knowledge especially in mathematical concept formation (Lopez-Real \& Leung, 2006). This is achieved by fostering visualization and exploration of mathematical concepts (Hohenwarter, Jarvis \& Lavicza, 2009).

Apart from exploring the impact of flipped classroom with simulation on the learning of vectors, the findings of this study will also benefit the society, especially when there is an increasing significance of home learning in recent years. Due to the outbreak and spread of COVID-19, many countries have announced or implemented school closures in order to reduce the risk involved in face-to-face class instruction. As a result, over 290 million students cannot attend school (Unesco, 2020). The teaching and learning at school are greatly disrupted, and it becomes a great crisis to traditional face-to-face instructional approach. This study sheds light to how schools and teachers can ensure the continued study for the students under such special circumstances. By integrating flipped learning with simulation, face-to-face teacher-and-student interaction could be minimized.

In this study, a positive effect on academic performance is hypothesized. This hypothesis is tested by a mixed research, with pre- and post-test being used to measure the academic performance. Interviews are also conducted to explore contributing factors behind the differences in performance. If flipped learning with simulation is statistically proved to improve students' academic performance in mathematics, it could be used as an alternative to the traditional face-to-face instructional approach. In aid of further researches, it may also serve as a prototype of AI education.

\section{Research Questions}

The key research questions are:

- What is the effect of a flipped classroom with PhET simulation on students' learning outcome in vectors?

A. If it is more effective, how does it enhance students' learning?

B. If it is not as effective as expected, what is/are the reason(s) obstructing students' learning?

- What is the school leader's perception of the flipped classroom with PhET simulation?

\section{Literature Review}

\subsection{Difficulties in Learning Vectors}

Learning vectors is by no means easy. Even university students are confused with vector direction, vector addition, tip-to-tail rule and parallelogram addition rule (Nguyen \& Meltzer, 2003). When it comes to high-school students, who are considered less intelligently mature, it is not surprising that they find learning vectors a challenging task.

According to Sari, Suyanto \& Suana (2017), only $39.1 \%$ of high school students understand the vector concept. Further evidence of high-school students' incompetence in vectors can be found in public examination results. According to Pearson Examiner Report (2015), some students showed a lack of understanding of vector quantities. Full mark for the question was rare with a significant number of students achieving little or no credit. Also, errors in the sign of vectors were fairly common at some stages of the working, and a number of students failed to find the magnitude of their position vector (Pearson Examiner Report, 2010). In addition, students struggled with the parallel idea or direction of vectors. As exemplified in Pearson Examiner Report (2013), most students incurred losses of points in a question which involved two parallel vectors. When they began to approach the question, the majority of students seemed to realize that something had to be equated to zero (See Figure 1: Q7(c)(i)). But only half of candidates took it to be the i-component of $v$, and the remainders mistakenly concluded that the $\mathbf{j}$-component should be zero or both components were equated to zero. The outcome revealed that a large proportion of students did not understand the rationale behind the question and the difficulties they had with the direction of vectors reflected limitations in the traditional teaching approaches of vectors. 
7. [In this question, the horizontal unit vectors $\mathbf{i}$ and $\mathbf{j}$ are directed due east and due north respectively.]

The velocity, $\mathrm{v} \mathrm{m} \mathrm{s}^{-1}$, of a particle $P$ at time $t$ seconds is given by

$$
\mathbf{v}=(1-2 t) \mathbf{i}+(3 t-3) \mathbf{j}
$$

(a) Find the speed of $P$ when $t=0$

(b) Find the bearing on which $P$ is moving when $t=2$

(c) Find the value of $t$ when $P$ is moving

(i) parallel to $\mathbf{j}$,

(ii) parallel to $(-\mathbf{i}-3 \mathbf{j})$.

Figure 1. Question 7 of Pearson Edexcel GCE Mechanics M1 Paper on 13 May 2013 (Pearson Edexcel, 2013)

\subsection{Why Flipped Classroom?}

Flipped classroom is a promising instructional method that may complement with traditional classes. Long in history, knowledge is transferred inside a classroom by a teacher. Despite the great value and limited amount of class time, unfortunately about $23-24 \%$ of it is lost across an academic year through timetabling, teacher absenteeism, lesson start and finish times and off-task activities (Little, Shojo, Sonnadara \& Aturupane, 2019). The price that comes with this undesirable situation is that students are deprived of the precious opportunities to construct knowledge on their own in class.

Flipped classroom offers a potential remedy to this problem by arranging the knowledge transfer process outside the classroom. It allows students to have access to the content before class through media and video recorded materials (Sierra, 2010). The saved class time can be used for activities in order to construct knowledge. More specifically, more in-class time could be spent on explaining difficult concepts or working on problems with guidance (Delozier \& Rhodes, 2017). Also, the process of knowledge construction is optimized by leveraging revolutionary changes to the teaching process (Wang, Jou, Lv \& Hung, 2018). Reidsema, Hadgraft \& Kavanagh (2017) believed that flipped learning is an important transition stage. "It is moving both students and academic staff away from the traditional lectures, an approach that has been in use since middle ages. Classrooms are becoming places for activity rather than information transfer." (p.10) Case-based presentation, student presentation, discussion, expert-led discussion, role-play and debates are activities utilized within flipped classes (O'Flaherty \& Phillips, 2015).

\subsection{Current Problems/Issues of Using Flipped Classroom}

Although flipped classroom has its own features and advantages, it cannot solve all classroom problems. Firstly, there is limited evidence on students' learning outcomes using flipped classroom model (O'Flaherty \& Phillips, 2015). Also, Molnar (2017) found that there was no significant difference in the learning outcome between the flipped classroom approach and the traditional face-to-face classroom approach. Furthermore, flipped classroom may not be suitable for all subjects (O’Flaherty \& Phillips, 2015).

\subsection{What Is Interactive Computer Software?}

In many countries, there is a growing tendency of using computer software in mathematics teaching in order to make the learning process more interesting and diverse. Numerous software is available to support the teaching and learning of mathematics, and dynamic geometry software (DGS) is one of the prominent forms (Dockendorff \& Solar, 2017). It is also referred to as dynamic mathematics software, mathematics visualization software or dynamic geometry environments. Some commonly used ones include Cabri, GeoGebra and PhET simulation, all of which are user-friendly DGS for teachers and students.

\subsection{Why Dynamic Geometry Software (DGS)?}

Teachers are encouraged to integrate DGS into their teaching and students are encouraged to interact with DGS (Chan \& Leung, 2014). According to the systematic review and meta-analysis of Chan and Leung (2014), DGS was found to have a positive influence on students' mathematical performance in all levels of education. They pointed out that a short period (less than two weeks) duration of DGS intervention was more effective in improving students' mathematics 
achievement than a longer treatment. Additionally, DGS offers students an opportunity to create their own dynamic geometry constructions in an interactive and visual learning environment (Zengin, 2018). Consequently, the abstract concepts can be visualized. (Denbel, 2015; Hohenwarter, Jarvis \& Lavicza, 2009). This is particularly important for students to absorb knowledge because they rely on visualization in determining the concepts and connecting prior knowledge with the statement (Rofii, Sunardi, \& Irvan, 2018). As an important tool of DGS, dragging allows students to observe the effects by selecting one or more objects and move them freely and continuously on the screen (González \& Herbst, 2009). This marks a great leap from traditional approach in which visualization cannot be achieved without pencil and paper. Also, the calculations of dragging are automatically generated, thereby empowering students to test their hypothesis or explore new features with immediate feedback (Polášek \& Sedláček, 2015).

\subsection{What Is Physics Education Technology (PhET) Simulation?}

PhET simulation, which is one of the DGS, is free and can be found from the PhET website (https://phet.colorado.edu/). Founded in 2002 by Nobel Laureate Carl Wieman, the PhET Interactive Simulations project at the University of Colorado Boulder offers user-friendly software which operate through standard web browsers. Among over 150 simulations available, "Build a fraction" is one of the simulations about mathematics. Users can build fractions from shapes and numbers to earn stars. "Vector Addition" (VA) is one of the simulations related to vectors, covering the basic concepts of vectors such as vector representations, angular form \& component form of vectors and adding vectors.

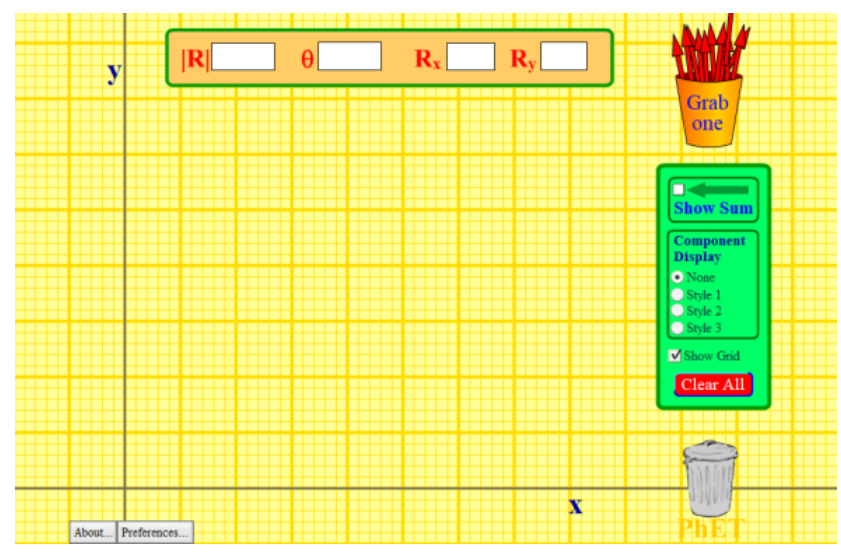

Figure 2. Interface of PhET simulation "Vector Addition" (VA)

Figure 2 shows an interface of VA. A vector is represented as an arrow, which can be obtained from the quiver on the right-hand-side with a mouse. The arrow can be pulled on the xy-plane, with the user controlling its length and direction. On the top, four values $(|R|, \theta, R x, R y)$ related to the vectors are generated automatically. When the user drags the arrow, these four values change correspondingly. This interactive process makes relationships between the arrow and these values more visible to the learners. When using this simulation, students can explore the topic (vectors) on their own by making a connection between an arrow and a vector, which can be manipulated directly with a mouse. Changes in values are instantly shown when they put two or more vectors together, increasing the effectiveness of using PhET simulation.

There are many advantages of PhET simulation. Firstly, it is fun and attractive (Wieman, Adams \& Perkins, 2008). Secondly, the invisible concept can be made more tangible. The visual representations can show the invisible concepts (Wieman, Adams \& Perkins, 2008). This is a great asset and facilitates learning since students rely on visualization in determining the concepts and connecting prior knowledge with the statement (Rofii, Sunardi, \& Irvan, 2018). Furthermore, a common visualization between students and the teacher aids communication and instruction (Wieman, Adams, Loeblein, \& Perkins, 2010). Thirdly, students learn better when they engage in self-driven exploration (Wieman \& Perkins, 2006; Wieman, Adams \& Perkins, 2008). It has improved students' conceptual understanding and insight into the nature of science (Clark \& Chamberlain, 2014). Fourthly, dragging allows students to test their hypothesis or explore new features with immediate feedback (Polášek \& Sedláček, 2015). Lastly, students who used simulations performed better on conceptual questions related to the topic (Finkelstein, Adams, Keller, Kohl, Perkins \& Podolefsky, et al., 2005). 


\subsection{Flipped Classroom With Simulation Could Be Helpful}

To summarize, poor academic results in vectors are widely observed in the past few years and limitations in teaching vectors with the traditional lecture are evident. Students encounter difficulties in relating mathematical concepts to graphical representations (Klein, Viiri, Mozaffari, Dengel, \& Kuhn, 2018). As analyzed above, PhET simulation may be helpful in the teaching of vectors when it is integrated into the traditional classroom. However, the use of PhET simulation in-class is always neglected due to the restricted in-class time. This drawback could be compensated by the introduction of Flipped classroom, which leaves students plenty of time to construct their knowledge in class after preparing for the learning contents beforehand. Nevertheless, it should be underscored that flipped classroom approach is not a one-off solution. Previous reports demonstrate that students' academic outcome could not be enhanced by flipped classroom approach alone. As shown by the work of Author (2020b), effect of flipped classroom could be significantly increased when it is enriched by other teaching and learning components. In view of its value and associated problems, flipped classroom with PhET simulation is suggested. PhET simulation VA, which is related to vectors, is believed to improve students' conceptual understanding of vectors by visualization and manipulation. Figure 3 shows the conceptual framework of this study.

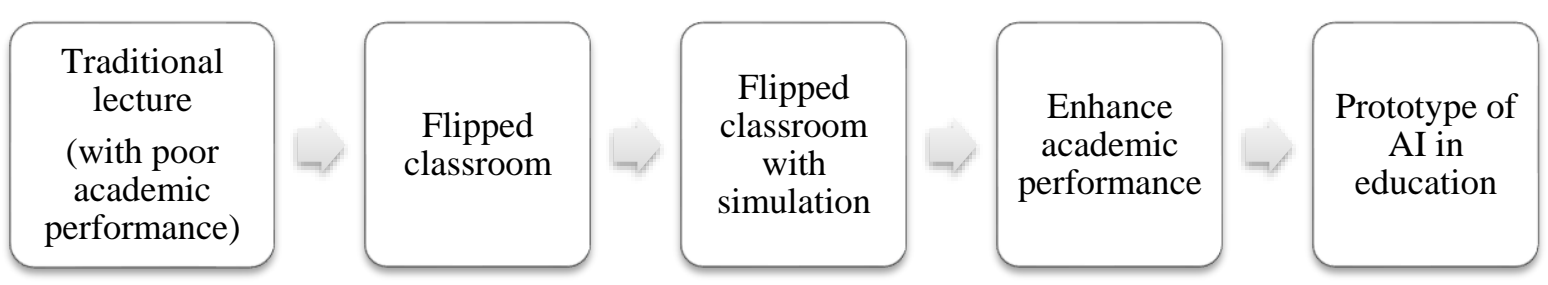

Figure 3. Steps of the conceptual framework

\section{Method}

The teaching method proposed in this study is to integrate PhET simulation into the flipped classroom model. The pre-class activity suggested is video-watching, while the in-class activity suggested is an exploration with a PhET simulation VA followed by an 80-minute lesson. Many researchers suggested flipping for the whole course or on a long-term basis (Greener, 2015; Wang et al., 2018; Lo \& Hew, 2017). Nevertheless, it is not necessary to flip an entire course. Kavanagh, Reidsema, McCredden \& Smith (2017) maintained that "Flipping classroom should be based on a need to help students master a particular concept or knowledge that is tricky and not being adequately mastered through a current delivery method" (p17). As a result, flipped classroom should be structured on the basis of learning need.

The study was conducted at a public high school in Guangdong Province of Mainland China. One class in Grade 11 was selected by convenient sampling. 18 students $(N=18)$ were recruited for the experiment, with half of them being male students. Before the experiment, all students were given a letter explaining the study, including a consent form with the contact of the researchers. While students could show their reluctance to being involved in the experiment by contacting the researchers, no students objected to participation. This study employed a quasi-experimental approach by comparing the pre-test and post-test result of the subjects. Students were asked to attend a pre-test (20 minutes) before the intervention. Then two short videos about the basic concept of vectors were assigned to students, who were expected to watch the videos in the duration of 5 to 6 minutes before class. Following this, each of them was provided with a computer and engaged in an 80-minute lesson where they were asked to use a PhET simulation VA to revise their learning by drawing vectors and to answer questions on a worksheet previously distributed. After the intervention, a 20 minutes post-test was conducted. The full score for pre-test and post-test was both 22 . While questions in the two tests differed slightly from each other, difficulty was carefully maintained at the same level. Figure 4 shows the flow of this research. 


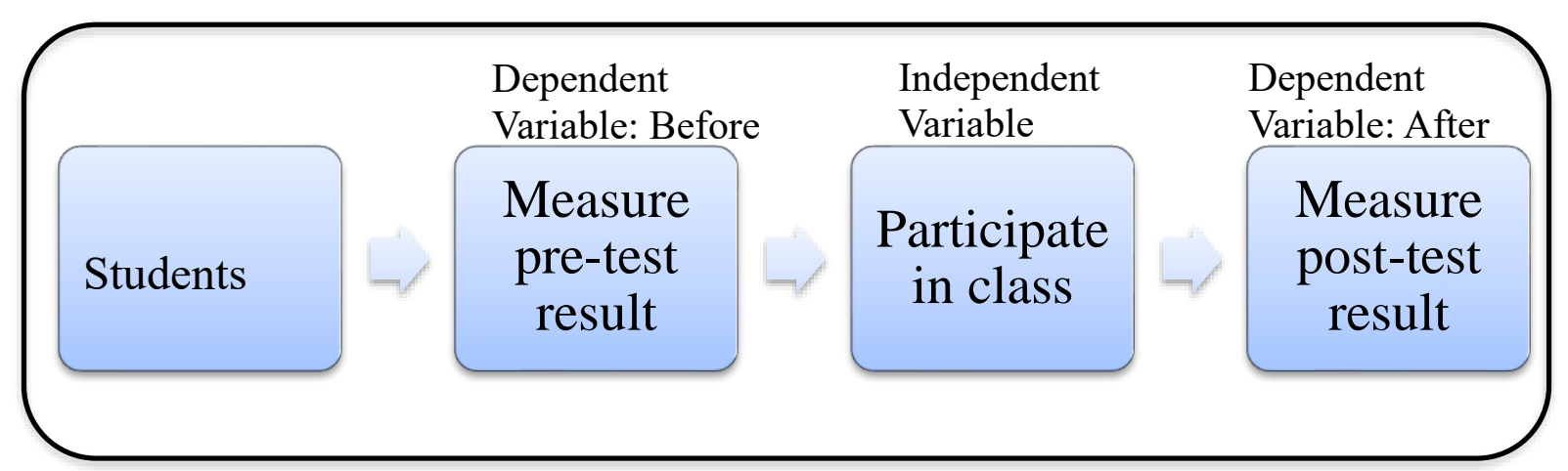

Figure 4. Flow of the research

On the next day after the post-test, five interviews were conducted. The first four targeted at student subjects while the last one was on an assistant principal who had about 10 times of teaching experiences with flipped classroom at that school.

Qualitative data and responses from open-ended questions were collected by the research through individual face-to-face interviews. Interviews were administered in an empty classroom and were conducted in Mandarin which is the mother tongue of participants. All interviews were audio-recorded and the interview data were verbatim transcribed. Both quantitative and qualitative data were processed using SPSS25 and coding respectively.

\subsection{Design of Worksheets}

The design of worksheets involved the concept of "Scaffolding". Wood, Bruner \& Ross (1976) defined scaffolding as "the process that enables a child or novice to solve a problem, carry out a task, or achieve a goal which would be beyond his unassisted efforts" (p.90). The six steps stated by Wood, Bruner \& Ross (1976) were recruitment, reduction in degrees of freedom, direction maintenance, frustration control and demonstration.

1. Recruitment. The first question aimed at engaging the students. They were asked to kick off by completing some calculations with their pen, ruler and calculator.

2. Reduction in degrees of freedom. Students were then required to accomplish several small tasks, e.g. dragging a vector and reading the information regarding the vector.

3. Direction maintenance. Students were asked to drag more vectors with different length or different direction. Also, they had to keep reading the information regarding the vectors.

4. Marking critical features. Students were asked to write down the meaning or representation of the arrow and angle of the vectors. Following that, they were paired in groups to perform the addition of vectors and to find the resultant vector by using the Tip-to-Tail method. Discussion was allowed during this process.

5. Frustration control. The teacher stayed in the computer room and gave advice to the students when needed. The teacher explained the $\mathbf{i}-\mathbf{j}$-notation of vectors to students before they attempted the practice questions.

6. Demonstration. The teacher showed clear steps of how to answer questions to the students. Finally, the teacher demonstrated the correct answer.

\section{Ethics Concerns}

Before the interview, participants were told that the interview would be audio-recorded and consents were obtained from all participants. To protect the confidentiality, the names of schools, teachers and students will not appear in any publication of the findings and data will be destroyed within two years.

\section{Results}

Table 1. $t$-test Results Comparing Pre- and Post-test Scores

\begin{tabular}{ccccc}
\hline & $\begin{array}{c}\text { Std. } \\
\text { Pre- \& Post-test }\end{array}$ & t & df & $\begin{array}{c}\text { Sig. } \\
\text { (2-tailed) } \\
\text { Mean }\end{array}$ \\
& 1.719 & 5.818 & 17 & .000 \\
\hline
\end{tabular}




\subsection{RQ1: Significant Improvement Could Be Observed in Students'Learning Outcome}

A paired-samples t-test was conducted, and the comparison between the pre-test and post-test results is shown in Table 1. The results show that flipped classroom could significantly improve students' academic performance with $\mathrm{t}(17)=5.818, \mathrm{p}<.001$. It further suggests that flipped classroom using simulation is an effective means in fostering students' learning outcome in terms of exam scores.

6.1.1 RQ1A: Positive Perception, Visualization, Dragging and Active Learning Are the Essential Factors Behind the Success

Interviewed data have been coded in the light of the second research question, which aims to investigate how the intervention improves the learning performance of vectors. Quotes from the interview are presented in Table 2 and used for illustrative purposes.

First of all, students pointed out that they were pleased with flipped classroom with simulation VA. When asked about their perceptions towards PhET simulation, they mostly associated it with positive feelings. It means they generally hold a positive attitude and are opened-minded to the intervention. This can be attributed to the interactive setting where students were fully concentrated and less distracted.

Moreover, students who experienced the simulation expressed that they could visualize the vector concepts. Words such as "see", "visualize" or "display" were frequently elicited in the response from the interviewees. They pointed out that the tangible visual images would facilitate their understandings and they could reason based on what they had seen on the screen. A telling example can be found in Figure 5 where it is very difficult for the teacher to explain why the $2 \mathbf{i}+2 \mathbf{j}$ is parallel to the $3 \mathbf{i}+3 \mathbf{j}$ since the algebraical expression does not provide many hints for students. It may require a great effort, especially for the less capable students, to identify that the ratio of $\mathbf{i}$ and $\mathbf{j}$ are the same, and thus $2 \mathbf{i}+2 \mathbf{j}$ and $3 \mathbf{i}+3 \mathbf{j}$ are pointing to the same direction (parallel). However, with the help of the PhET simulation, the abstract concept (direction) could now be visualized on the screen, and the directions of the vectors $(2 \mathbf{i}+2 \mathbf{j}$ and $3 \mathbf{i}+3 \mathbf{j})$ could be observed intuitively. The application of IT-assisted teaching not only allows the answer to be obtained with greater ease, but also facilitates students' reasoning power since the figures provide more hints of how the algebraical expressions (e.g. $2 \mathbf{i}+2 \mathbf{j}$ ) are derived.
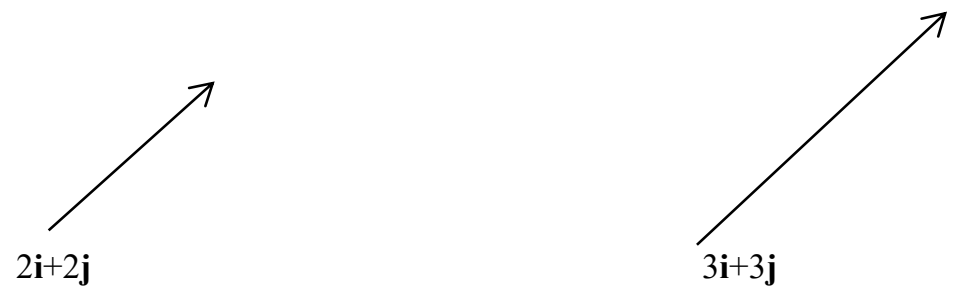

Figure 5. Visualization of $2 \mathbf{i}+2 \mathbf{j}$ and $3 \mathbf{i}+3 \mathbf{j}$

Meanwhile, the dragging provided the platform for students to verify their hypothesis and thus better understand manipulated vectors. For example, students who could not immediately indicate that $2 \mathbf{i}+2 \mathbf{j}$ and $3 \mathbf{i}+3 \mathbf{j}$ are pointing to the same direction could try to "prove" it. By dragging " $2 \mathbf{i}+2 \mathbf{j}$ " to " $3 \mathbf{i}+3 \mathbf{j}$ ", students soon realized that " $2 \mathbf{i}+2 \mathbf{j}$ " was totally aligned on the " $3 \mathbf{i}+3 \mathbf{j}$ ". Based on this line of reasoning, students may form an assumption that $x \mathbf{i}+x \mathbf{j}$ is also parallel to $2 \mathbf{i}+2 \mathbf{j}$ where $x$ is an arbitrary real number. This hypothesis can be verified by constructing a vector, e.g. $5 \mathbf{i}+5 \mathbf{j}$, and dragging it onto the " $2 \mathbf{i}+2 \mathbf{j}$ ". As a result, students' understanding could be deepened by forming and confirming/rejecting their own equations. With positive attitudes, visualization and dragging, active learning is thus facilitated. This is in stark contrast with a traditional classroom where students act as passive learners who are expected to follow and learn abstract knowledge delivered by the teacher and/or textbooks.

Since the teaching materials are pre-constructed, the "range" of the learning contents is relatively fixed and limited. However, it does not imply that students are expected to be "passive learners". Conversely, they are encouraged to think outside the box and be curious about the unknown world. When students are given the chance to explore the teaching content themselves, they are more willing to understand the rationale behind theories and generate their own hypothesis accordingly. 


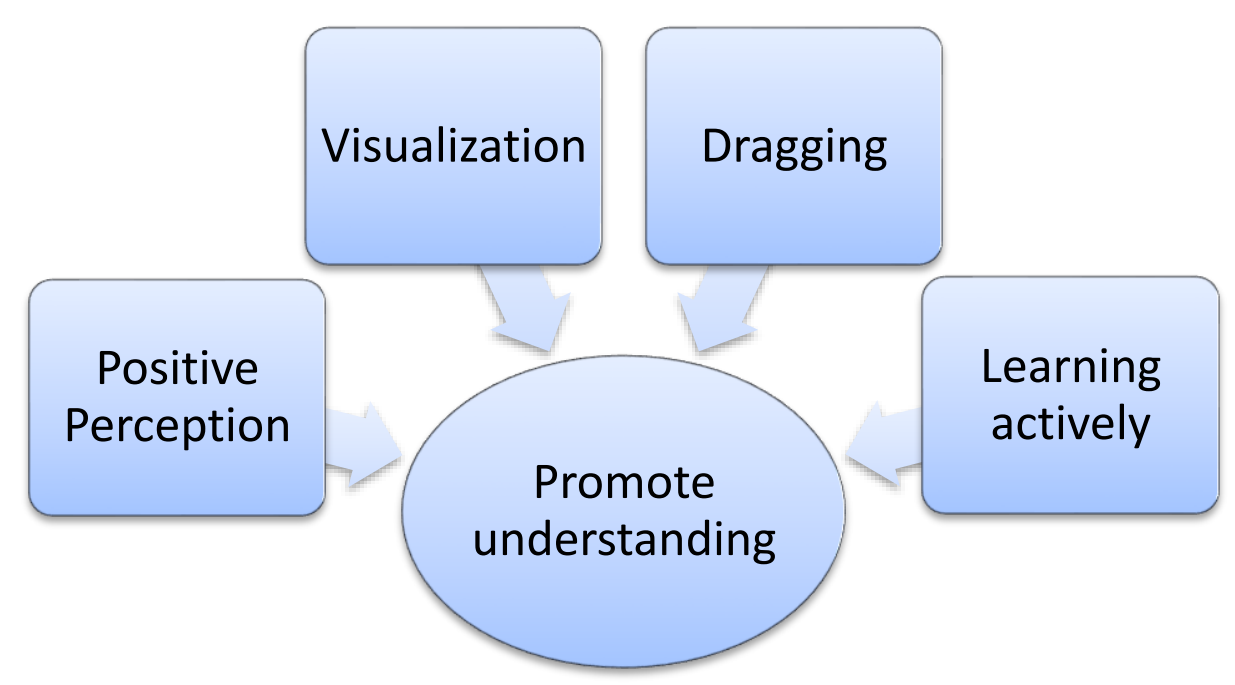

Figure 6. A representation of the results in four categories 
Table 2. Factors improve the learning outcome of students

\begin{tabular}{|c|c|c|}
\hline Category & Codes & Quotes \\
\hline Feeling & $\begin{array}{l}\text { more fun }(\mathrm{N}=1) \\
\text { more interactive }(\mathrm{N}=1) \\
\text { less distracted }(\mathrm{N}=1) \\
\text { works better }(\mathrm{N}=2) \\
\text { pretty much prefer }(\mathrm{N}=2) \\
\text { not bad }(\mathrm{N}=1) \\
\text { impressed }(\mathrm{N}=1) \\
\text { a nice try }(\mathrm{N}=1) \\
\text { stimulates curiosity }(\mathrm{N}=1) \\
\text { novel teaching }(\mathrm{N}=1) \\
\text { works fine for me }(\mathrm{N}=1)\end{array}$ & $\begin{array}{l}\text { It made me less distracted, and I found it easier for me } \\
\text { to understand. (S1) }\end{array}$ \\
\hline Visualization & $\begin{array}{l}\text { see }(\mathrm{N}=4) \\
\text { displays }(\mathrm{N}=2) \\
\text { actually see }(\mathrm{N}=1) \\
\text { visually illustrated }(\mathrm{N}=1) \\
\text { visualize the concept }(\mathrm{N}=1) \\
\text { graphic representations of numbers } \\
(\mathrm{N}=1) \\
\text { gave us tangible visual images }(\mathrm{N}=1)\end{array}$ & $\begin{array}{l}\text { We could actually see how vectors changed in different } \\
\text { forms. This gave us tangible visual images of an } \\
\text { abstract notion of maths. I would say it facilitated } \\
\text { our understanding. (S2) } \\
\text { I was impressed by its graphic representations of } \\
\text { numbers...I can visualize the concepts through } \\
\text { graphic representations. (S3) }\end{array}$ \\
\hline Dragging & $\begin{array}{l}\text { manipulating by ourselves }(\mathrm{N}=1) \\
\text { manipulating vectors in several } \\
\text { formats }(\mathrm{N}=1) \\
\text { can drag vectors }(\mathrm{N}=1) \\
\text { moving the mouse }(\mathrm{N}=1) \\
\text { manipulate the vectors myself }(\mathrm{N}=1)\end{array}$ & $\begin{array}{l}\text { Because we find it easier to understand after } \\
\text { manipulating by ourselves. (S1) } \\
\text { We had the firsthand experience on manipulating } \\
\text { vectors in several formats, which turned abstract } \\
\text { concepts into concrete ones. (S2) }\end{array}$ \\
\hline $\begin{array}{l}\text { Learning } \\
\text { actively }\end{array}$ & $\begin{array}{l}\text { trials and errors }(\mathrm{N}=1) \\
\text { our own trials on the software }(\mathrm{N}=1) \\
\text { work on our own }(\mathrm{N}=1)\end{array}$ & $\begin{array}{l}\text { The new teaching strategy works better because the } \\
\text { interactive software allows me to manipulate the } \\
\text { vectors myself rather than receiving knowledge } \\
\text { passively, which enhances my understanding of the } \\
\text { concepts...I have never resorted to this learning } \\
\text { strategy, which requires us, students, to work on our } \\
\text { own and thus stimulates our curiosity and widens } \\
\text { our thinking. We are no longer restricted by fixed } \\
\text { ideas imposed on ourselves without truly } \\
\text { understanding the mechanism behind theories. (S4) }\end{array}$ \\
\hline
\end{tabular}

\subsection{RQ2: Positive Response From School Principal}

To get a brief idea about school leader's view on flipped classroom with simulation, an assistant principal responsible for school administration was interviewed. The result could be divided into two parts: 6.2.1 perception in terms of fostering teaching performance and 6.3 perception in terms of administrative reasons.

\subsubsection{Fostering Teaching Performance: Simulation Allows Better Monitoring}

As indicated in the interview, school leader viewed favorably of flipped classroom and he believed that it could foster students' understanding and facilitate the in-class activities. However, close monitoring of students is needed to ensure the learning goals could be achieved. A common occurrence throughout the study was that when discussion, which was 
a popular component in flipped classroom, was employed as the in-class activities, there was no guarantee that students would engage in discussing the teaching content as expected. Some of them would go astray and discuss irrelevant topics in the absence of monitoring guidance from the teacher. With the help of the simulation, it is easier for the teacher to monitor the students' learning behavior as all the buttons and functions provided in the simulation are already fixed and pre-determined by the teacher, which allows better monitoring in students' learning progress.

6.2.2 Fostering Teaching Performance: Flipped Classroom With Simulation May Enhance Student' Confidence and Metacognitive Skills

Interestingly, after observing the lesson enriched by flipped classroom with simulation, the interviewee highlighted potential benefits brought by the use of simulation. From his own experience, one of the common phenomena among science stream students is that they are always expecting a "correct" answer from the teacher. Although students have come up with their own alternative methods in solving a question, they still look for teachers' affirmation to gain confidence. In this case, the authority displayed by teachers significantly hinders the efficacy of discussion as an in-class activity. In face of this dilemma, simulation may have a role to play. When functions and equations are all set, values could be calculated automatically in the simulation, which fosters students' self-confidence by confirming their hypothesis and alternative methods. Testing their hypothesis by trial-and-error using the simulation will invariably enhance students' planning skills, and metacognitive skills in large.

\subsection{Administrative Reasons for Supporting Flipped Classroom With Simulation (See Figure 7)}

\subsubsection{Reducing Teachers' Workload}

According to the interviewee, one of the most amazing merits of using flipped classroom with simulation is the significant reduction of the teacher's workload. Since the learning goals and the teaching content are well monitored, it does not require much assistance from teachers when students are using the simulation when compared to the traditional flipped classroom. Therefore, the teachers' workload could be dramatically lessened once the materials are well developed.

\subsubsection{Promoting the Roles of Teacher to Monitoring Level}

Followed by the reduction of teachers' workload in class, the burden of delivering knowledge is released, and teacher could focus more on the students' learning progress at the macro level. Since the main knowledge delivering process is now conducted by simulation, teacher could now focus more on what should be delivered and how to present. The function of the teachers therefore shifts from the executor to the director, curriculum planner, synthesizer and manager. In other words, the role of the teacher is promoted to a senior level so that he/she could direct, control and monitor the learning process.

\subsubsection{Flipped Classroom With Simulation as an Effective Distance-Learning Model}

Since the use of simulation could greatly reduce the reliance on teacher during the knowledge delivery process, it implies that flipped classroom with simulation may be adopted in distance learning. By shifting the knowledge delivering process from face-to-face interactions to computer-to-student, the knowledge delivering process could now be accomplished outside the school, thus supplementing traditional teaching methods and enriching the flexibility in both learning and teaching. 


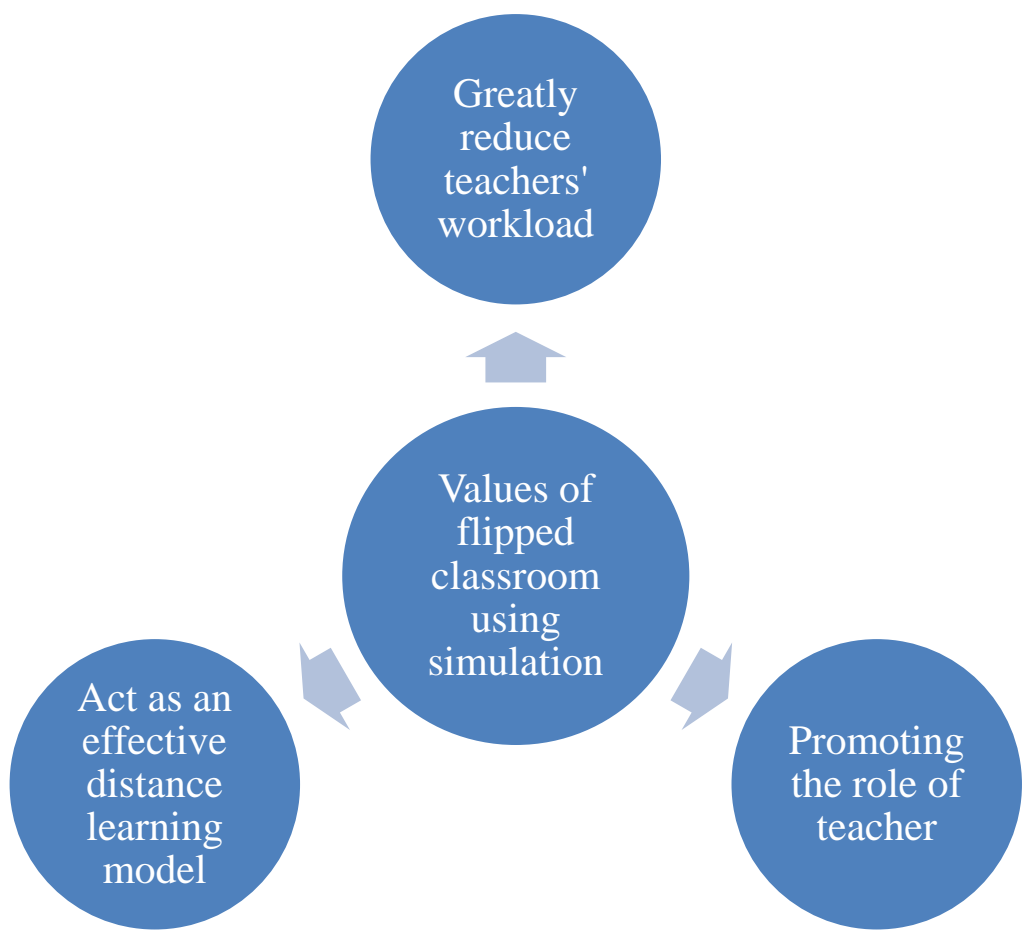

Figure 7. Values of flipped classroom using simulation in the view of the school leader

\section{Discussion}

\subsection{To Be or Not to Be, That Is the Question}

Recently, challenges hindering the development of flipped classroom are constantly being reported. This can be seen in interviews in this study where classroom management was a listed as a major concern. The effect of flipped classroom could be weakened by students who were not self-disciplined and could not resist the temptation of computer games. Therefore, restraints are suggested to be placed in the computers so that the teacher could monitor the learning activities by using the remote desktop program.

While the implementation of flipped classroom is subject to changes and improvement in individual school setting, its significance can never be underestimated. According to the results of this study, one of the most important values of flipped classroom with simulation is that it can be used as an alternative, reliable and effective teaching method, especially when face-to-face lecture is not possible. While classroom teaching has been adopted as the mainstream type of teaching and learning model in most schools all over the world, it does not mean that it is always accessible to educators and learners alike. For instance, during the spread of severe acute respiratory syndrome (SARS) in 2002-2003 and COVID-19 in 2020, there was a large-scale class suspension in Asian countries, making it impossible to organize face-to-face teaching. The lack of interactive contact between teachers and students makes knowledge delivery less effective, if not entirely interrupted. In this case, flipped classroom with simulation could potentially contribute to tackling the challenges. As revealed by this study, flipped classroom with simulation could be used in traditional schools without compromising interactions in person. As such, it has the potential to be used as an effective distance learning model in which the learning process is primarily achieved by using video and simulation. Geographic separation and the absence of face-to-face interactions will no longer be an issue, which means school education does not need to be suspended during campus closure.

As analyzed above, mastering flipped classroom with simulation is essential because it allows schools to have more flexibility in terms of knowledge delivery. It is suggested that about $10 \%$ of the classes should be aided by flipped classroom.

\subsection{Flipped Classroom With Simulation as a Helpful Pedagogy to Robot Teacher}

In digital age, a growing number of social roles in our lives are taken up by robots, and whether the role of teachers could be replaced by robots has been heatedly debated (Sharkey, 2016). Although effective to some extent, there are still challenges which the robot teachers have to overcome before they are widely adopted in our education system (Belpaeme, Kennedy, Ramachandran, Scassellati, \& Tanaka, 2018). For example, educators generally believe that an AI 
teacher is not as creative as human counterparts because it could only deliver in a way which they have been programmed to do (Ivanov, 2016, June). There is a lack of effective teaching and learning pedagogies among robot teachers (Belpaeme et al., 2018); as a result, fully-fledged robot teachers are not welcomed (Sharkey, 2016).

Flipped classroom with simulation may be an ideal supplement to robot teachers. This study has demonstrated that flipped classroom with simulation could ignite active learning among students by providing the fundamental knowledge. It could also promote students' curiosity to explore and test their hypothesis by trial-and-error. A dynamic platform in the simulation boosts their imagination and inspires them to approach questions with different methods. Therefore, integrating simulation in classroom teaching with robot teachers may be more welcomed and become a paradigm in practice.

\section{Limitations \& Further Study}

A major limitation of this study is the absence of control group. Only one class of students was recruited and no comparison could be made between the control group and the experimental group. An additional limitation is about the sample size, which involved only 18 students and 1 school leader. A note of caution should also be sounded about the geographical limitation because only Mainland China students were targeted in the study, which could undermine the generalization of results. Last but not least, student satisfaction about the intervention, which can be measured by Likert scale or free-text responses, remains to be investigated.

Limitations rendered above suggest that studies comparing the effect between flipped classroom with simulation and conventional teaching approaches are in need. Researchers are advised to repeat the experiment in different topics and at different locations. Moreover, studies which investigate the similarity and difference between flipped classroom with simulation and traditional flipped classroom are also suggested to determine whether human teachers could be completely replaced by simulation.

\section{Conclusion}

The successful integration of PhET simulation into flipped classroom brings about positive changes in the teaching and learning of vectors. Evidence from research shows that flipped classroom with PhET simulation contributes to the success of both teaching and learning process. Students excelled academically and had a better understanding of vector concepts because of visualization, dragging and active learning aided by PhET simulation.

In the unavailability of campus teaching due to special circumstances such as the pandemic of COVID-19, flipped classroom with simulation may assist students' learning progress. By shifting the role of teachers from executors to facilitators in the teaching process, it marks a promising prototype of $\mathrm{AI}$ in education.

\section{References}

Author. (2020a). International Journal of Mathematical Education in Science and Technology.

Author. (2020b). Technology, Knowledge and Learning.

Barniol, P., \& Zavala, G. (2009). Investigation of students' preconceptions and difficulties with the vector direction concept at a Mexican university. Proceedings of the American Institute of Physics (AIP) Conference, 1179, 85-88. https://doi.org/10.1063/1.3266761

Belpaeme, T., Kennedy, J., Ramachandran, A., Scassellati, B., \& Tanaka, F. (2018). Social robots for education: A review. Science robotics, 3(21), eaat5954. https://doi.org/10.1126/scirobotics.aat5954

Bishop, J. L., \& Verleger, M. A. (2013). The flipped classroom: a survey of the research. In 120th ASEE National Conference and Exposition, Atlanta, GA (Paper ID 6219). Washington, DC: American Society for Engineering Education.

Chan, K. K., \& Leung, S. W. (2014). Dynamic geometry software improves mathematical achievement: systematic review and meta-analysis. Journal of Educational Computing Research, 51(3), 311-325. https://doi.org/10.2190/EC.51.3.c

Clark, T. M., \& Chamberlain, J. M. (2014). Use of a PhET Interactive Simulation in General Chemistry Laboratory: Models of the Hydrogen Atom. Journal of Chemical Education, 91(8), 1198-1202. https://doi.org/10.1021/ed400454p

Curriculum Development Council \& the Hong Kong Examinations and Assessment Authority (CDC \& HKEAA) (2017). Mathematics Curriculum and Assessment Guide (Secondary 4 - 6). HK: Education Bureau.

Delozier, S. J., \& Rhodes, M. G. (2017). Flipped classrooms: a review of key ideas and recommendations for practice. Educational Psychology Review, 29(1), 141-151. https://doi.org/10.1007/s10648-015-9356-9 
Denbel, D. G. (2015). Students' learning experiences when using a dynamic geometry software. Journal of Education \& Practice, 6.

Dockendorff, M., \& Solar, H. (2017). ICT integration in mathematics initial teacher training and its impact on visualization: the case of GeoGebra. International Journal of Mathematical Education, 49(46), 1-19. https://doi.org/10.1080/0020739X.2017.1341060

Finkelstein, N. D., Adams, W. K., Keller, C. J., Kohl, P. B., Perkins, K. K., \& Podolefsky, N. S., et al. (2005). When learning about the real world is better done virtually: a study of substituting computer simulations for laboratory equipment. Physical Review Special Topics - Physics Education Research, 1(1), 010103. https://doi.org/10.1103/PhysRevSTPER.1.010103

González, G., \& Herbst, P. G. (2009). Students' conceptions of congruency through the use of dynamic geometry software. International Journal of Computers for Mathematical Learning, 14(2), 153-182. https://doi.org/10.1007/s10758-009-9152-z

Greener, S. (2015). Flipped or Blended? What's the Difference and Does it Make a Difference to Learning in HE? Proceedings of the International Conference on e-Learning, 146-151. Bahamas: College of the BahamasNassau.

Hohenwarter, M., Jarvis, D., \& Lavicza, Z. (2009). Linking Geometry, Algebra and Mathematics Teachers: GeoGebra Software and the Establishment of the International GeoGebra Institute. International Journal for Technology in Mathematics Education, 16(2), 83-87.

Ivanov, S. H. (2016, June). Will robots substitute teachers?. In 12th International Conference "Modern science, business and education (pp. 27-29).

Kavanagh, L., Reidsema, C., McCredden, J., \& Smith, N. (2017). Design Considerations. In C. Reidsema et al. (Eds.), The flipped classroom: Practice and Practices in Higher Education. (pp. 15-35). Singapore: Springer. https://doi.org/10.1007/978-981-10-3413-8_2

Klein, P., Viiri, J., Mozaffari, S., Dengel, A., \& Kuhn, J. (2018). Instruction-Based Clinical Eye-Tracking Study on the Visual Interpretation of Divergence: How Do Students Look at Vector Field Plots? Physical Review Physics Education Research, 14(1), 010116-010111. https://doi.org/10.1103/PhysRevPhysEducRes.14.010116

Knight, R. D. (1995). Vector knowledge of beginning physics students. The physics teacher, 33, 74-78. https://doi.org/10.1119/1.2344143

Little, A. W., Shojo, M., Sonnadara, U., \& Aturupane, H. (2019). Teaching English as a Second Language in Sri Lankan Primary Schools: Opportunity and Pedagogy. Language, Culture and Curriculum, 32(2), 113-27. https://doi.org/10.1080/07908318.2018.1532437

Lo, C. K., \& Hew, K. F. (2017). Using "First Principles of Instruction" to design secondary school mathematics flipped classroom: the findings of two exploratory studies. Educational technology \& Society, 20(1), 222-236. https://doi.org/10.18178/ijlt.3.2.82-89

Lopez-Real, F., \& Leung, A. (2006). Dragging as a conceptual tool in dynamic geometry environments. International Journal of Mathematical Education in Science and Technology,37(6), 665-679. https://doi.org/10.1080/00207390600712539

Molnar, K. K. (2017). What effect does flipping the classroom have on undergraduate student perceptions and grades? Education and Information Technologies, 22(6), 2741-2765. https://doi.org/10.1007/s10639-016-9568-8

Nguyen, N. L., \& Meltzer, D. E. (2003). Initial understanding of vector concepts among students in introductory physics courses. American Journal of Physics, 71(6), 630-638. https://doi.org/10.1119/1.1571831

O'Flaherty, J., \& Phillips, C. (2015). The use of flipped classrooms in higher education: A scoping review. The Internet and Higher Education, 25(C), 85-95. https://doi.org/10.1016/j.iheduc.2015.02.002

Pearson Edexcel (2010). Examiners' Report of Summer 2010. GCE Mechanics M1. UK: Pearson Education Ltd.

Pearson Edexcel (2013). Examiners' Report of Summer 2013. GCE Mechanics M1. UK: Pearson Education Ltd.

Pearson Edexcel (2013). GCE Mechanics M1 Advanced/Advanced Subsidiary (paper reference:6677/01). UK: Pearson Education Ltd.

Pearson Edexcel (2015). Examiners' Report of Summer 2015. GCE Mechanics M1. UK: Pearson Education Ltd.

Pearson Edexcel (2016). Examiners' Report of Summer 2016. GCE Core Mathematics 4. UK: Pearson Education Ltd. 
Pearson Edexcel (2018). Pearson Edexcel International Advanced Level in Mathematics, Further Mathematics and Pure Mathematics: Specification. UK: Pearson Education Ltd.

POLÁŠEK \& SEDLÁČEK (2015). Dynamic Geometry Environments as Cognitive Tool in Mathematics Education. Journal of Technology and Information Education, 7(2), 45-54. https://doi.org/10.5507/jtie.2015.017

Reidsema, C., Hadgraft, R., \& Kavanagh, L. (2017). Introduction to the flipped classroom. In C. Reidsema et al. (Eds.), The flipped classroom: Practice and Practices in Higher Education. (pp. 3-14). Singapore: Springer. https://doi.org/10.1007/978-981-10-3413-8

Rofii, A., Sunardi, \& Irvan, M. (2018). Characteristics of students' metacognition process at informal deduction thinking level in geometry problems. International Journal on Emerging Mathematics Education, 2(1), 89-104. https://doi.org/10.12928/ijeme.v2i1.7684

Sari, W. P., Suyanto, E., \& Suana, W. (2017). Analisis Pemahaman Konsep Vektor pada Siswa Sekolah Menengah Atas. Jurnal Ilmiah Pendidikan Fisika Al-BiRuNi, 6(2): 159-168.

Sharkey, A. J. (2016). Should we welcome robot teachers? Ethics and Information Technology, 18(4), 283-297. https://doi.org/10.1007/s10676-016-9387-z

Sierra, J. (2010). Shared responsibility and student learning: ensuring a favorable educational experience. Journal of Marketing Education, 32(1), 104. https://doi.org/10.1177/0273475309344802

Unesco. (2020). 290 million students out of school due to COVID-19: UNESCO releases first global numbers and $\begin{array}{lllll}\text { mobilizes response } & \text { [Press } & \text { release]. } & \text { Retrieved }\end{array}$ https://en.unesco.org/news/290-million-students-out-school-due-covid-19-unesco-releases-first-global-numbers-an d-mobilizes

Wang, J. Y., Jou, M., Lv, Y. Z., \& Huang, C. C. (2018). An Investigation on Teaching Performances of Model-based Flipping Classroom for Physics Supported by Modern Teaching Technologies. Computers in Human Behavior, 84, 36-48. https://doi.org/10.1016/j.chb.2018.02.018

Wieman, C. E., \& Perkins, K. K. (2006). A powerful tool for teaching science. Nature Physics, 2(5), 290-292. https://doi.org/10.1038/nphys283

Wieman, C. E., Adams, W. K., \& Perkins, K. K. (2008). Physics: phet: simulations that enhance learning. Science, 322(5902), 682-683. https://doi.org/10.1126/science.1161948

Wieman, C. E., Adams, W. K., Loeblein, P., \& Perkins, K. K. (2010). Teaching physics using phet simulations. The Physics Teacher, 48(4), 225. https://doi.org/10.1119/1.3361987

Wood, D., Bruner, J. S., \& Ross, G. (1976). The role of tutoring in problem solving. Journal of Child Psychology and Psychiatry, 17, 89-100. https://doi.org/10.1111/j.1469-7610.1976.tb00381.x

Zavala, G., \& Barniol, P. (2010). Students' understanding of the concepts of vector components and vector products. Proceedings of the American Institute of Physics (AIP) Conference, 1289, 341-344. https://doi.org/10.1063/1.3515240

Zengin, Y. (2018). Incorporating the dynamic mathematics software GeoGebra into a history of mathematics course. International Journal of Mathematical Education in Science and Technology, 49(7), 1083-1098. https://doi.org/10.1080/0020739X.2018.1431850

\section{Copyrights}

Copyright for this article is retained by the author(s), with first publication rights granted to the journal.

This is an open-access article distributed under the terms and conditions of the Creative Commons Attribution license which permits unrestricted use, distribution, and reproduction in any medium, provided the original work is properly cited. 